\title{
The "pre-assembled state" of magainin 2 lysine-linked dimer determines its enhanced antimicrobial activity
}

\author{
Esteban N. Lorenzón ${ }^{a}$,*, Thatyane M. Nobre ${ }^{a}$, Luciano Caseli $^{\mathrm{b}}$, Eduardo M. Cilli ${ }^{\mathrm{c}}$, \\ Gabriel C.A. da Hora ${ }^{d}$, Thereza A. Soares ${ }^{d}$, Osvaldo N. Oliveira Jr. ${ }^{a}$ \\ a Instituto de Física de São Carlos, Universidade de São Paulo, São Carlos, SP, Brazil \\ b Institutode Ciências Ambientais, Químicas e Farmacêuticas, Universidade Federal de São Paulo, Diadema, SP, Brazil \\ ${ }^{\mathrm{c}}$ Institutode Química, Universidade Estadual Paulista, Araraquara, SP, Brazil \\ d Departamentode Química Fundamental, Universidade Federal de Pernambuco, Recife, PE, Brazil
}

\section{A R T I C L E I N F O}

\section{Article history:}

Received 23 February 2018

Received in revised form 9 April 2018

Accepted 16 April 2018

Available online 20 April 2018

\section{Keywords:}

Antimicrobial peptides

Dimerization

Molecular dynamics

Mechanism of action

Langmuir monolayer

Escherichia coli

\begin{abstract}
A B S T R A C T
Antimicrobial peptides (AMPs) are alternatives to conventional antibiotics against multi-drug resistant bacteria with low potential for developing microbial resistance. The design of such molecules requires understanding of the mechanisms of action, particularly the interaction with bacteria cell membranes. In this work, we determine the mechanism responsible for the higher activity against Escherichia coli of the C-terminal lysine dimer of magainin 2, $(\mathrm{MG} 2)_{2} \mathrm{~K}$, in comparison to the monomeric peptide magainin 2 (MG2). Langmuir monolayers and vesicles made with the $E$. coli lipid extract were used to address the two possible states for the peptide-membrane interaction, namely the "binding state" and "pore state", respectively. The incorporation of MG2 and (MG2) ${ }_{2} \mathrm{~K}$ in lipid monolayers at the air-water interface caused slight differences in surface pressure isotherms and polarization-modulated infrared reflection absorption (PM-IRRAS) spectra, and therefore the difference in activity is not associated with the binding state. In contrast, large differences were observed in the leakage experiments where $(\mathrm{MG} 2)_{2} \mathrm{~K}$ was shown to disrupt the large unilamellar vesicles to a much higher extent owing to efficient pore formation. The binding and penetration of MG2 and (MG2) ${ }_{2} \mathrm{~K}$ were also probed with molecular dynamics (MD) simulations for bilayers made with 1-palmitoyl-2-oleoyl-sn-glycero-3-phosphoethanolamine:1-palmitoyl-2-oleoyl-snglycero-3-phosphoglycerol (POPE:POPG). (MG2 ${ }_{2} \mathrm{~K}$ forms disordered toroidal pores at a significant lower concentration than for MG2. In summary, the combination of experimental and computational simulation results indicated that the "pre-assembling state" of $(\mathrm{MG} 2)_{2} \mathrm{~K}$ dimer leads to a reduced number of molecules and shorter time being required to kill E. coli.
\end{abstract}

(c) 2018 Elsevier B.V. All rights reserved.

\section{Introduction}

The spread of pathogenic microorganisms resistant to antibiotics has increased beyond the pace with which new antibiotics are approved for commercialization [1], and this represents a global health problem with social and economic impact [2]. There is thus an urgent need for new molecules to control diseases caused by resistant microorganisms, such as the antimicrobial peptides (AMPs) that are promising because they act through mechanisms against which pathogens rarely develop resistance $[3,4]$. In contrast to conventional antibiotics, which exert their toxic activity

\footnotetext{
* Corresponding author. Present address: Universidade Federal de Goiás, Instituto de Ciências Biológicas, Departamento de Bioquímica e Biologia Molecular, ICB II sala: 118, Campus II Samambaia, 74690-900, Goiania, GO, Brazil.

E-mail address: esteban@ufg.br (E.N. Lorenzón).
}

by binding to specific targets, most AMPs act by destabilizing the cell membrane [5]. The majority of these peptides have features in common such as cationic character, high percentage of hydrophobic amino acids, amphipathic nature and tendency to adopt helical structures in membranes [6-8].

Magainin 2 (MG2) is a host-defense AMP discovered on the skin of Xenopus laevis that acts on the lipid matrix of membranes of microorganisms, killing Gram-negative and Gram-positive bacteria, fungi and protozoa $[9,10]$. The interaction of MG2 with the phospholipids comprising cell membranes has been studied via a variety of biophysical methods and computational simulations from which it has been inferred that MG2 forms toroidal pores in lipid bilayers [11-13]. However, the detailed molecular mechanism of action is not fully understood [14]. So far, it seems that aggregation of AMPs on the membrane surface is a prerequisite [15] regardless of the kind of mechanism of action 
(pore or solubilization). Enhanced antimicrobial activity has been obtained for dimerized peptides, which are also advantageous for their increased solubility and resistance against proteases [16-19]. However, the relation between AMP dimerization and increased biological activity is not a general rule since some dimeric peptides lose their activity, or are very toxic to mammalian cells [20-23]. In a recent study, we showed that C-terminal dimerization of MG2 affects considerably its antimicrobial activity. The dimeric version (MG2) ${ }_{2} \mathrm{~K}$ was up to 16 times more efficient than MG2 to kill Escherichia coli, and required a fourth of the time of the monomer to exert its antimicrobial activity [24].

In this study, we aim at explaining those differencesby using model membranes. Towards this end, Langmuir monolayers and large unilamellar vesicles (LUVs) were prepared with the total lipid extract from $E$. coli and made to interact with MG2 and its derivative $(\mathrm{MG} 2)_{2} \mathrm{~K}$. The use of membrane models composed of total lipid extract obtained from $E$. coli, rather than traditional models composed of only two lipids, allowed us to correlate with results obtained with living cells. We also performed molecular dynamics (MD) simulations to characterize at the molecular level the effects of the "pre-assembling state" of $(\mathrm{MG} 2)_{2} \mathrm{~K}$.

\section{Experimental section}

\subsection{Peptide synthesis}

MG2 and (MG2) $2 \mathrm{~K}$ were manually synthesized by solid-phase peptide synthesis using standard 9-fluorenylmethyloxycarbonyl (Fmoc) protocols [25].

\subsection{Langmuir monolayers experiments}

Langmuir monolayers were prepared with E. coli total lipid extract (Avanti Polar Lipids, Inc.). A stock solution was prepared in chloroform:methanol $(4: 1 \mathrm{v} /: \mathrm{v})$. Adsorption kinetics and surface pressure isotherms experiments were performed in a mini-KSV Langmuir trough (KSV Instruments Ltd, Helsinki, Finland) equipped with a Wilhelmy plate made of filter paper. The isotherms were obtained by spreading $15 \mu \mathrm{L}$ of the lipid from a stock solution at $2 \mathrm{mg} \mathrm{mL}^{-1}$ on an aqueous subphase consisting of phosphate buffered saline (PBS) solution at $\mathrm{pH}$ 7.4. The spreading phospholipid solvents were allowed to evaporate for $15 \mathrm{~min}$, after which adsorption kinetics were obtained for different concentrations of the peptide by monitoring the surface pressure with time. After equilibrium, compression of the air-water interface was carried out using two movable barriers at $10 \mathrm{~cm}^{2} \mathrm{~min}^{-1}$. The Langmuir monolayers were also studied using polarization-modulated infrared reflection-absorption spectroscopy (PM-IRRAS) [26,27] with a KSV PMI 550 instrument (KSV Instruments Ltd, Helsinki, Finland) in a mini KSV Langmuir trough according to protocols described previously [28]. The experimental setup for isotherms was the same used above in Langmuir monolayers. Data was acquired at $30 \mathrm{mN} \mathrm{m}^{-1}$. The Langmuir trough was assembled so that the infrared light beam reached the monolayer at a fixed incidence angle of $80^{\circ}$. The incoming light was modulated at a frequency of $50 \mathrm{kHz}$ between $s$ - and $p$ polarizations, which allowed simultaneous measurements for both polarizations. All Langmuir monolayer experiments were carried out in a clean room at $21.0 \pm 0.1^{\circ} \mathrm{C}$.

\subsection{Large unilamellar vesicles (LUVs) experiments}

LUVs made of total lipids from $E$. coli were prepared by mixing $10 \mathrm{mg}$ of the lipid in a 4:1 (v/v) chloroform:methanol mixture in a round-bottom flask. The solvents were evaporated using nitrogen gas and placed under vacuum overnight. The dried lipid film was hydrated with a PBS solution containing $50 \mathrm{mmol} \mathrm{L}^{-1}$ of carboxyfluorescein $(\mathrm{CF})$. The suspension was subjected to 5 cycles of vortexing, sonication and heating at $60^{\circ} \mathrm{C}$. The resulting cloudy suspension was extruded 31 times through two stacked nucleopore polycarbonate filters (100 nm pore size) using an extruder system from Avanti Polar Lipids (Alabaster, AL, USA). The vesicles were separated from the non-encapsulated $C F$ by gel filtration on a Sephadex G-50 column using PBS for elution. The release of CF from LUVs was calculated from the measured fluorescence intensity at $517 \mathrm{~nm}$ (492 nm excitation wavelength) after addition of different concentrations of peptides. At the end of each experiment ( $9 \mathrm{~min})$, Triton $\mathrm{X}-100$ (1\%) was added to promote full CF leakage. All experiments were carried out at $25.0^{\circ} \mathrm{C}$. The percentage of $\mathrm{CF}$ leakage was given by Eq. (1):

\%leakage $=100(\mathrm{Ft}-\mathrm{Fo}) /(\mathrm{Fmax}-\mathrm{Fo})$

where Ft is the fluorescence at $9 \mathrm{~min}$, Fo is the initial fluorescence (before peptide addition), and Fmax is the maximum fluorescence after addition of Triton X-100 (1\%). Data were acquired using a fluorescence spectrophotometer (Cary Eclipse, Varian, Inc., Palo Alto, CA, USA). The experiments were performed at room temperature.

Circular dichroism (CD) spectra were obtained between 195 and $250 \mathrm{~nm}$ with a JASCO J-815 CD spectrophotometer (Japan) on nitrogen flush in 1-mm path-length quartz cuvettes at $25^{\circ} \mathrm{C}$. The peptide concentration was $50 \mu \mathrm{mol} \mathrm{L}^{-1}$. To investigate the conformational changes induced by membrane interaction, LUVs $\left(500 \mu \mathrm{mol} \mathrm{L}^{-1}\right)$ made with the total lipid extract from $E$. coli were used. CD spectra were recorded as an average of six scans.

\subsection{Computational simulations}

Molecular dynamics (MD) simulations were performed for the magainin-2 peptide (MG2) and the lysine-linked magainin-2 dimer $(\mathrm{MG} 2)_{2} \mathrm{~K}$ in solution and in membrane bilayers composed of 1-palmitoyl-2-oleoyl-sn-glycero-3-phosphoethanolamine (POPE) and 1-palmitoyl-2-oleoyl-sn-glycero-3-phosphoglycerol (POPG). A coarse-grained (CG) representation of atoms as described by the MARTINI force field $[29,30]$ was used in conjunction with the GROMACS v4.6.7 software package [31]. The structure of the dimer $(\mathrm{MG} 2)_{2} \mathrm{~K}$ was built from the atomic coordinates of the monomer MG2 obtained via NMR spectroscopy in micelles (PDB ID: 2MAG) [32]. The dimer (MG2) ${ }_{2} \mathrm{~K}$ comprised 47 residues with a net charge of $+8 e$. The $(\mathrm{MG} 2)_{2} \mathrm{~K}$ sequence was converted from an atomistic to a coarse-grained representation with generation of the corresponding topology through the Martinize 2.5 python script (http:// www.cgmartini.nl/index.php). A distance constraint was applied between the amine bead of the LYS24 side chain and the carbon bead of the SER47 backbone to mimic the isopeptide bond connecting the two MG2 to form (MG2) ${ }_{2} \mathrm{~K}$. The constraint distance was set to have the same length of the lysine linker. Two initial configurations were built for $(\mathrm{MG} 2)_{2} \mathrm{~K}$ : the folded configuration in which the two helices are folded and parallel to each other, and the stretched configuration in which the two helices are disposed at an angle of $180^{\circ}$ with regard to each other (Fig. S2 in Supplementary material). MD simulations were performed for $(\mathrm{MG} 2)_{2} \mathrm{~K}$ placed on lipid bilayers containing 520 lipid units in a $3: 1$ ratio of POPE:POPG, respectively. The CG membrane bilayer was built with the INSANE script [33]. The systems were energy-minimized and solvated with CG water molecules and $150 \mathrm{mM}$ of $\mathrm{NaCl}$, followed by a second round of energy minimization and equilibration for $2 \mu$ s under $N p T$ conditions. The simulated systems consisted of six or twelve copies of either the folded or stretched initial conformations (see Table S1 in Supplementary material). The choice of the number of peptide copies relied on previous coarse-grained simulations of MG2 in DPPC bilayers [13]. Periodic boundary conditions were applied in all directions on each rectangular simulation 

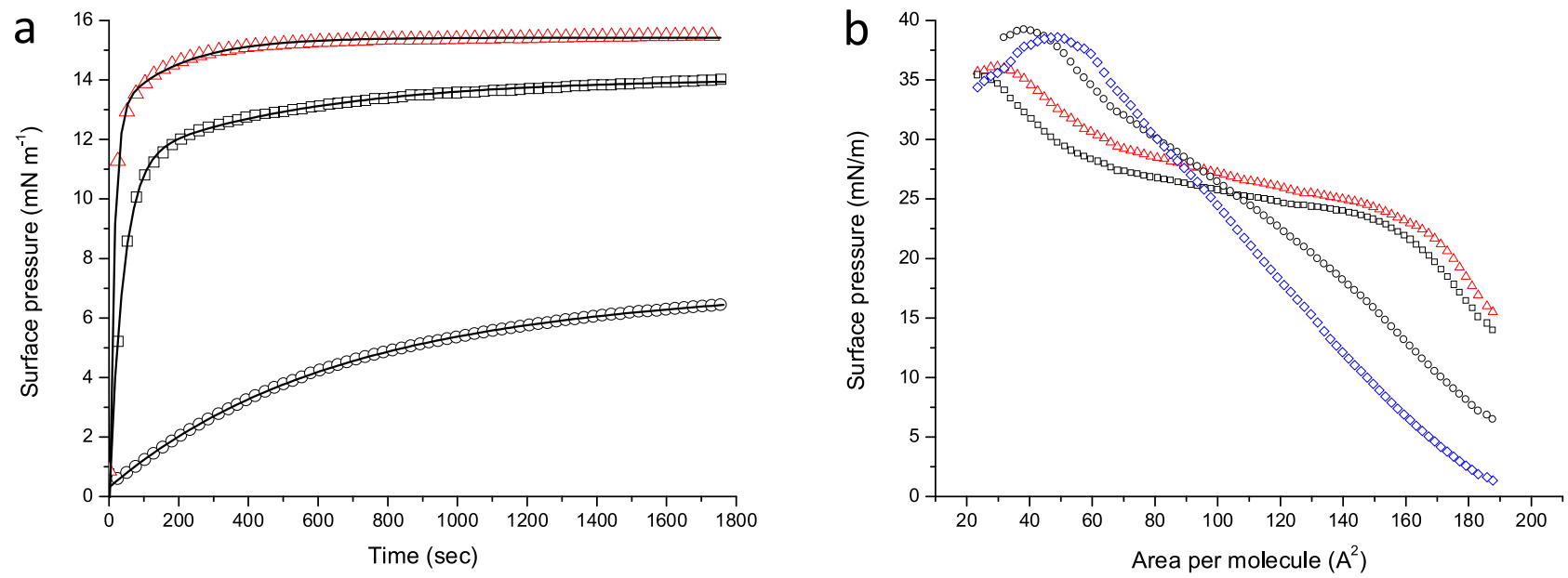

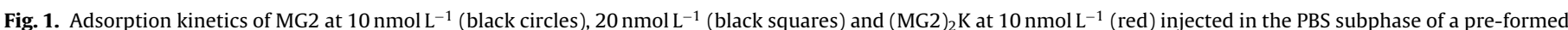

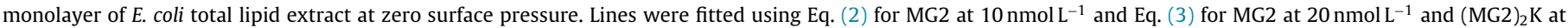

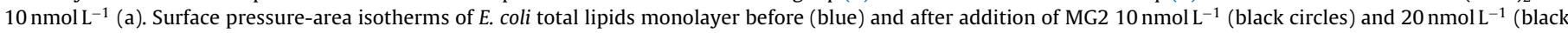

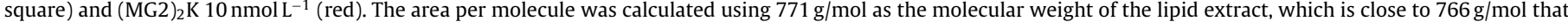

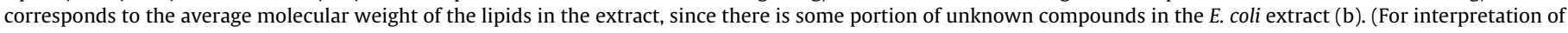
the references to colour in this figure legend, the reader is referred to the web version of this article.)

box. The systems were simulated using constant number of particles, pressure and temperature (NpT ensemble). The pressure was maintained at 1 bar using the Parrinello-Rahman scheme [34], semi-isotropically coupling the particles with a relaxation time of $0.1 \mathrm{ps}$ and a compressibility of $4.5 \times 10^{-5}\left(\mathrm{~kJ} \mathrm{~mol}^{-1} \mathrm{~nm}^{-3}\right)^{-1}$. Isotropic coupling with the same relaxation time was applied to simulations of the peptides in solution. The temperature was kept at $300 \mathrm{~K}$ by separately coupling the temperatures of the membrane bilayer, peptides and the solvent (with a time constant of $14.0 \mathrm{ps)}$ using velocity rescaling with a stochastic term [35]. Non-bonded interactions were cut off at $1.2 \mathrm{~nm}$ as suitable for the use of MARTINI force field. All the MD simulations were performed using a timestep of $0.02 \mathrm{ps}$. Time-dependent distribution of peptide and water molecules across the axis normal to the bilayer and partial density number of lipid functional groups were analyzed also using the GROMACS software package. The trajectories snapshots and coordinates were visualized using the software VMD v. 1.9.3 [36] with the $c g$ _bond and $c g$ helix scripts from the MARTINI website.

\section{Results and discussion}

MG2 is one of the first AMP described [9] and might be the most studied, whose bactericidal activity arises from leakage of cell contents via pores formed by the peptides [37-39]. Attempts to increase antimicrobial activity have been made with MG2 analogues [40-43], especially dimers $[24,44,45]$. The dimeric peptide $(\mathrm{MG} 2)_{2} \mathrm{~K}$ with a lysine residue as a linker, for instance, showed the highest antimicrobial activity among disulfide linked analogues, with faster killing of $E$. coli and 16-fold decrease in the minimum inhibitory concentration (MIC) [24]. Here we aim at comparing MG2 and (MG2) ${ }_{2} \mathrm{~K}$ in the light of prevailing models for their bactericidal activity, according to which the peptides form pores in the bacteria membrane with a two-step mechanims of peptidemembrane interaction: the "binding state" and the formation of a "pore state" [46]. Binding was simulated with Langmuir monolayers because we could have access to the adsorption kinetics and changes induced in the monolayer by the peptides, whereas the formation of pores was interrogated with vesicles (i.e. bilayer models) and MD simulations. We used the total lipid extract from E. coli to mimic the bacteria membrane, since working with living bacteria is presently not feasible for the type of molecular-level information we wish to obtain.

\subsection{Langmuir monolayers}

The action of AMPs on membranes is believed to start with their adsorption on the membrane owing to electrostatic forces $[15,47]$, and this may be probed by using tensiometry and vibrational spectroscopy on Langmuir monolayers [48-51]. Fig. 1a shows the adsorption kinetics for MG2 or (MG2) ${ }_{2} \mathrm{~K}$ injected into the PBS subphase of a pre-formed monolayer of $E$. coli total lipid extract at zero surface pressure. At $10 \mathrm{nmol} \mathrm{L}^{-1}$, adsorption of MG2 can be fitted with a single exponential function (Eq. (2)), whereas the adsorption kinetics was better represented by a double exponential function (Eq. (3)) as the concentration increased to $20 \mathrm{nmol} \mathrm{L}^{-1}$. Eq. (3) also applied to $(\mathrm{MG} 2)_{2} \mathrm{~K}$, at the concentration of $10 \mathrm{nmol} \mathrm{L}^{-1}$.

The equations used are as follows [52]:

$\Pi t=A 1 e^{-t / t 1}+\Pi f$

$\Pi t=A 1 e^{-t / t 1}+A 2 e^{-t / t 2}+\Pi f$

where $A_{1}$ and $t_{1}$ provide information on the amplitude and rate constant for peptide diffusion, rearrangement and folding and its adsorption onto the monolayer, while $A_{2}$ and $t_{2}$ are related to a slow increase in surface pressure with a plateau corresponding to equilibrium. $\Pi_{\mathrm{f}}$ is the final surface pressure $[52,53]$. The parameters used to fit the data are given in Table 1.

$A_{1}$ for MG2 at $10 \mathrm{nmol} \mathrm{L}^{-1}$ is half the value for the dimeric peptide at the same molar concentration. It means that the level of peptide adsorption is essentially constant for the number of monomeric units. In contrast, the time involved in peptide adsorption, $t_{1}$, is shorter for $(M G 2)_{2} \mathrm{~K}$ even when compared to MG2 at the same number of monomeric units $\left(20 \mathrm{nmol} \mathrm{L}^{-1}\right)$. This behavior could be associated with the more hydrophobic character of the dimeric peptide [24], leading to faster diffusion to the interface. In addition, the time to reach equilibrium $\left(t_{2}\right)$ is also shorter for the dimeric peptide while the relative contribution, in terms of surface pressure, is basically the same as that of MG2. These data show that the pre-assembled state of two peptide chains via covalent dimerization could increase the adsorption kinetics of peptides onto monolayers, probably owing to the increased hydrophobicity 
Table 1

Fitting parameters for peptide adsorption kinetics using Eqs. (2) and (3).

\begin{tabular}{|c|c|c|c|c|c|c|}
\hline Peptide/Conc $\left(\mathrm{nmol} \mathrm{L}^{-1}\right)$ & $\mathrm{A}_{1}\left(\mathrm{mN} \mathrm{m}^{-1}\right)$ & $\mathrm{t}_{1}(\mathrm{~s})$ & $\mathrm{A}_{2}\left(\mathrm{mN} \mathrm{m}^{-1}\right)$ & $\mathrm{t}_{2}(\mathrm{~s})$ & Order of fitting & $\mathrm{R}^{2}$ \\
\hline MG2/10 & $7.01 \pm 0.01$ & $693.87 \pm 1.94$ & & & 1 & 0.999 \\
\hline$M G 2 / 20$ & $11.51 \pm 0.02$ & $39.36 \pm 0.16$ & $2.84 \pm 0.01$ & $536.26 \pm 5.54$ & 2 & 0.998 \\
\hline$(\mathrm{MG} 2)_{2} \mathrm{~K} / 10$ & $14.22 \pm 0.07$ & $13.70 \pm 0.13$ & $2.59 \pm 0.04$ & $185.84 \pm 3.28$ & 2 & 0.988 \\
\hline
\end{tabular}
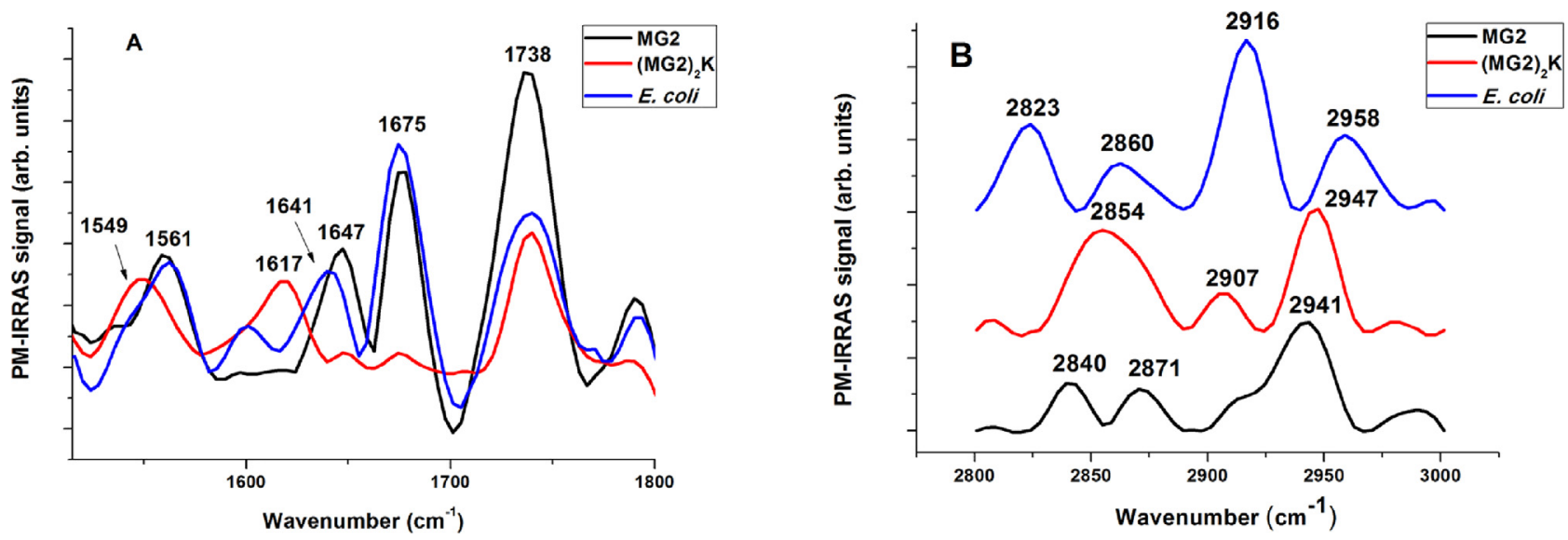

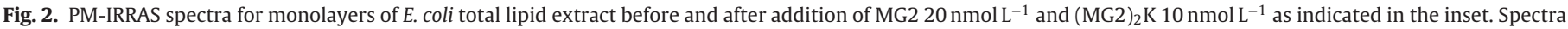
were taken at a surface pressure of $30 \mathrm{mN} \mathrm{m}^{-1}$.

and size of the dimeric peptide with the presence of the linker unit (lysine at the C-terminus).

The surface pressure isotherms for the Langmuir monolayers, obtained after adsorption of the peptides had reached equilibrium, are shown in Fig. 1b. With regard to the peptide concentration dependence, the results mirror those obtained in adsorption kinetics experiments. That is to say, for $10 \mathrm{nmol} \mathrm{L}^{-1}$ of MG2 the effect on the monolayer is considerably lower than for the higher $\left(20 \mathrm{nmol} \mathrm{L}^{-1}\right)$ concentration and for $10 \mathrm{nmol} \mathrm{L}^{-1}$ of $(\mathrm{MG} 2)_{2} \mathrm{~K}$. In all cases, the peptides are incorporated into the monolayer at large areas per molecule, causing an expected shift to larger areas in the surface pressure isotherms since the peptides are amphiphilic [54]. Upon compression, the isotherms for the peptide-containing monolayers intersect the isotherm for the pure lipid extract, which probably means that non-monomolecular structures could be formed in the more condensed states. This is especially the case for $20 \mathrm{nmol} \mathrm{L}^{-1}$ of MG2 and $10 \mathrm{nmol} \mathrm{L}^{-1}$ of $(\mathrm{MG} 2)_{2} \mathrm{~K}$, whose isotherms exhibit clear plateaus typical of phase transitions, and lead to much higher monolayer compressibility than for the neat lipid extract at the surface pressure believed to correspond to the packing of a real membrane (ca. $30 \mathrm{mN} \mathrm{m}^{-1}$ ). Also significant is that the isotherms for $20 \mathrm{nmol} \mathrm{L}^{-1}$ of MG2 and $10 \mathrm{nmol} \mathrm{L}^{-1}$ of (MG2) ${ }_{2} \mathrm{~K}$, i.e. with the same number of monomeric units, are similar. One could perhaps interpret this as the monolayer packing being affected to the same extent by either MG2 or (MG2) ${ }_{2} \mathrm{~K}$.

Molecular-level information on the interaction between the peptides and the lipid extract was obtained by taking the PM-IRRAS spectra of monolayers at $30 \mathrm{mN} \mathrm{m}^{-1}$. The spectrum for the neat E. coli lipid extract in Fig. 2A displays the expected $\mathrm{C}=\mathrm{O}$ stretching bands owing to lipid headgroups at $1738 \mathrm{~cm}^{-1}$. The band at $1675 \mathrm{~cm}^{-1}$ may be attributed to residual proteins in the lipid extract (amide I band) or to $\mathrm{O}-\mathrm{H}$ bending vibration of reoriented water molecules resulting from the differencial spectra of the convered surface in relation to the uncovered one (subtracted background spectra). The band at $1561 \mathrm{~cm}^{-1}$ is assigned to $\mathrm{C}-\mathrm{N}$ bending mode (amide II band) and those at 1617 and $1641 \mathrm{~cm}^{-1}$ are assigned to $\mathrm{C}=\mathrm{O}$ stretching modes (amide I band). The bands related to amide vibrations were not expected and are probably associated with protein residues in the extract which contained $\sim 17 \%$ of unknown material, according to the manufacturer. We could not identify bands specific for the peptides in the spectra of Fig. 2A, either because at a high pressure the peptides may not be exposed at the air/aqueous interface or because (most probably) their bands could have been masked by those of protein residues in the E. coli extract. Incorporation of MG2 caused changes in the relative intensity of $\mathrm{C}=\mathrm{O}$ bands assigned to the lipids, possibly related to reorientation of the $\mathrm{C}=\mathrm{O}$ group since the PM-IRRAS signal is highly dependent on dipolar orientation. The only significant band shift induced by MG2 occurred in the $\mathrm{C}=0$ amide I band, which shifted from $1641 \mathrm{~cm}^{-1}$ to $1647 \mathrm{~cm}^{-1}$, pointing to a change in the polypeptide secondary structure from parallel-chain sheets to $\alpha$-helices [55]. The effects from (MG2) ${ }_{2} \mathrm{~K}$ were considerably greater, with disappearance of the band at $1675 \mathrm{~cm}^{-1}$ and considerable shifts for the amide I and amide II bands. This reveals a more significant change in molecular structure for the dimer.

Fig. 2B shows the spectra for the hydrophobic region of the lipids, where the stretching modes of $\mathrm{C}-\mathrm{H}$ appear. For the $\mathrm{E}$. coli lipid extract, the bands at 2916 and $2823 \mathrm{~cm}^{-1}$ are attributed to $\mathrm{CH}_{2}$ groups, for asymmetric and symmetric stretching respectively, whereas the bands at 2958 and $2860 \mathrm{~cm}^{-1}$ are assigned to $\mathrm{CH}_{3}$ groups, for asymmetric and symmetric stretching, respectively. The bands are remarkably changed by insertion of the peptides, pointing to their effect on the hydrophobic structure of the lipid monolayer. For (MG2) ${ }_{2} \mathrm{~K}$, some bands are shifted to lower energies: 2947, $2907 \mathrm{~cm}^{-1}$ attributed respectively to $\mathrm{CH}_{3}$ asymmetric and $\mathrm{CH}_{2}$ asymmetric stretching. A wide band at $2854 \mathrm{~cm}^{-1}$ appears possibly due to coupling of the bands related to symmetric stretching of $\mathrm{CH}_{3}$ and $\mathrm{CH}_{2}$ groups. For MG2, the bands assigned to asymmetric stretching are also shifted to lower wavenumbers (2941 and $2910 \mathrm{~cm}^{-1}$, the latter one as a shoulder), but the bands assigned to symmetric stretching appear split at 2871 and $2840 \mathrm{~cm}^{-1}$. The shifts to lower energies, the loss of band definition and the changes in relative intensity induced by the peptides indicate that the packing order has diminished to a more random-like nature [56]. These findings are consistent with our MD simulations (see below) of $(\mathrm{MG} 2)_{2} \mathrm{~K}$ in membrane bilayers which show the formation of disordered toroidal pores. These would be a kind of pore in which the 

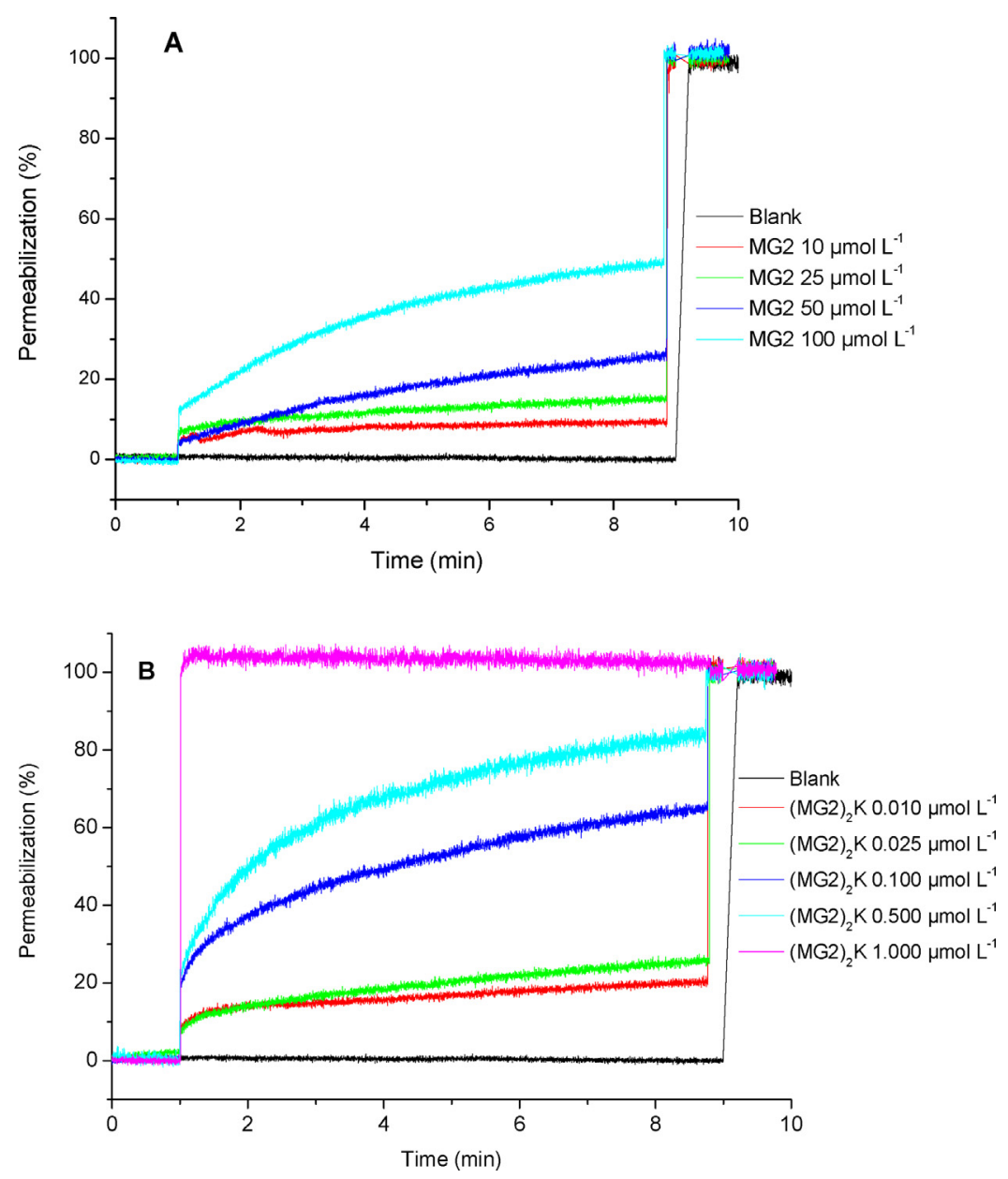

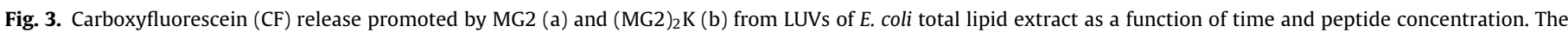
peptide was added after 1 min and Triton X-100 (1\% v/v) was added after 9 min to obtain 100\% leakage.

orientations of the peptides are not well defined, as in an intermediate situation between the carpet and toroidal pathways [57].

From the data of Langmuir monolayers experiments, particularly the PM-IRRAS, we noted that peptides induced stronger effects on the alkyl chains than in the hydrophilic region. These results are consistent with the mechanism of action of these peptides, believed to be related to formation of pores through the membrane. However, no significant differences were found between MG2 and $(\mathrm{MG} 2)_{2} \mathrm{~K}$.

\subsection{Large unilamellar vesicles}

Further information on the interaction of the peptides with membranes was sought using LUVs of E. coli total lipid extract as a bilayer model, with which permeabilization and CD experiments were performed. LUVs encapsulating CF have been proven excellent for studying AMP activity without using living bacteria $[58,59]$. Fig. 3 shows the CF-release profile for different peptide concentrations, featuring a higher activity of the dimeric peptide. MG2 was not able to reach $100 \%$ of permeabilization even at $100 \mu \mathrm{mol} \mathrm{L}^{-1}$, while (MG2) ${ }_{2} \mathrm{~K}$ was already active at $0.01 \mu \mathrm{mol} \mathrm{L}^{-1}$ and produced $100 \%$ of permeabilization at $1 \mu \mathrm{mol} \mathrm{L}^{-1}$. Furthermore, leakage increased linearly with MG2 concentration (which is in agreement with a previous work of Zerweck [60]), while for $(\mathrm{MG} 2)_{2} \mathrm{~K}$ the increase was exponential (Fig. S1 in Supplementary material).

CD studies were performed to investigate the secondary structure of the peptides in the presence of LUVs at a 10 lipid to peptide
(L/P) molar ratio. This ratio was chosen because a low peptide concentration produce weak signal, while higher lipid concentrations increase sample turbidity. At $\mathrm{L} / \mathrm{P}$ ratio of 10 , the amount of peptide is sufficient to saturate the vesicles. (LUVs contain approximately 100,000 lipids each. With a L/P ratio of 10 , there are about 10,000 peptides bound to each vesicle, capable of complete saturation). Fig. 4 shows that both peptides have a random coil structure in PBS. However, in contact with LUVs, MG2 changed to a welldefined helicoidal structure with the typical double minima at 209 and $222 \mathrm{~nm}$ and a maximum at around $195 \mathrm{~nm}$. This result is consistent with our previous study where we used the secondary structure-inducing solvent trifluoroethanol and lysophosphatidylcholine micelles [24]. In contrast, (MG2) ${ }_{2} \mathrm{~K}$ interacted strongly with the LUVs generating a cloudy dispersion that leads to an undefined spectrum.

In the experiments with vesicles, interaction of (MG2) ${ }_{2} \mathrm{~K}$ with the $E$. coli membrane model was considerably stronger than for MG2, according to vesicle permeabilization and CD data. Most significantly, leakage experiments revealed differences in terms of peptide concentration dependence. Dye release increased exponential and resulted in full lysis of the membrane at very low concentrations for $(\mathrm{MG} 2)_{2} \mathrm{~K}$. In contrast, MG2 caused a linear increase of leakage and was not able to induce full leakage at concentrations tested. The change from a linear to an exponential increase could be related to a change in the mechanism of action of the peptides, from classical toroidal pores to disordered toroidal pores. In previous work with the AMP aurein 1.2, we have also shown that dimerization led to a distinct mechanism of action 


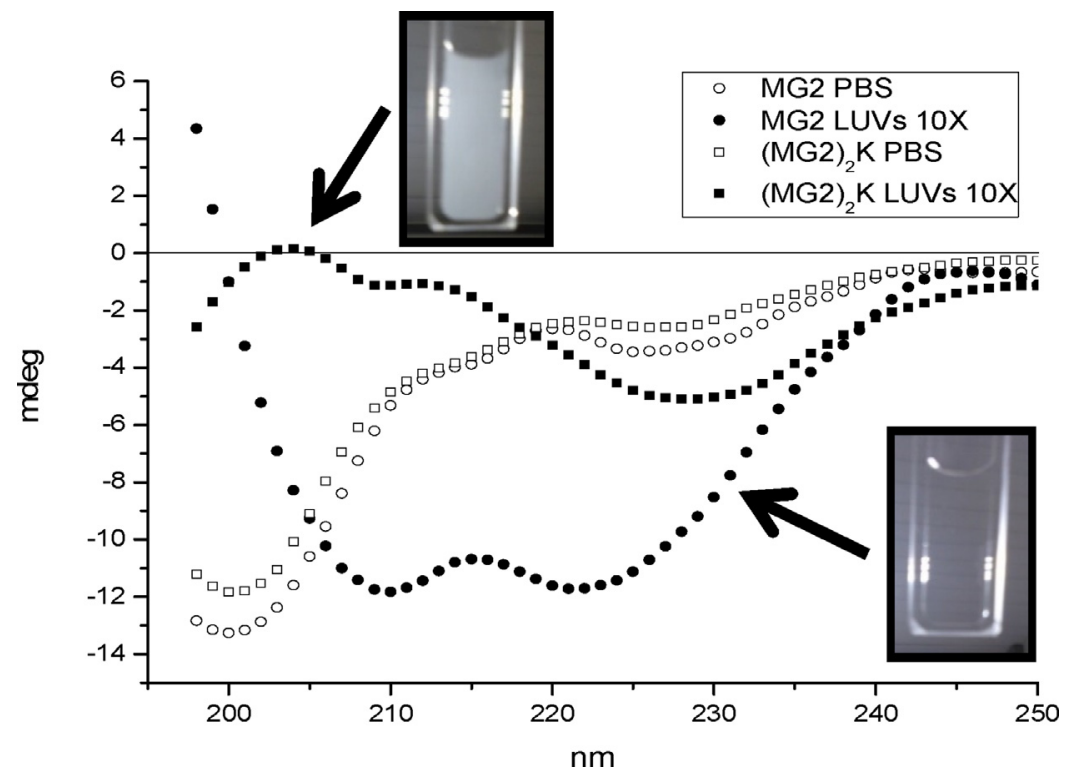

Fig. 4. CD spectra of the monomeric and dimeric peptide $\left(50 \mu \mathrm{mol} \mathrm{L}^{-1}\right)$ in PBS and LUVs $\left(500 \mu \mathrm{mol} \mathrm{L}^{-1}\right)$ made from the total lipid extract from E. coli.

[61]. The differences between (MG2) 2 K and MG2 were so large that it was not possible to compare effects using the same number of monomeric units as we did for the Langmuir monolayers. Therefore, the main difference between monomer and dimer occurs with bilayers rather than in monolayers.

\subsection{Computational simulations}

MD simulations were performed for a single copy of $(\mathrm{MG} 2)_{2} \mathrm{~K}$ in solution, and for multiple copies of MG2 and $(\mathrm{MG} 2)_{2} \mathrm{~K}$ in POPE:POPG bilayers. MG2 has been shown to occur in a helical conformation both in solvent and DPPC micelles [32]. Simulations of $(\mathrm{MG} 2)_{2} \mathrm{~K}$ in solvent started either from a stretched or a folded conformation with both systems converging to the same compact, folded conformation (Fig. S2 in Supplementary material). These results indicate that (MG2) 2 K adopts a folded conformation prior to bilayer adsorption. Nevertheless, for the sake of completeness, we considered both (MG2) ${ }_{2} \mathrm{~K}$ conformations, stretched and folded, in the MD simulations of the dimer in presence of the membrane bilayer. Furthermore, we considered different concentrations and arrangements of MG2 and (MG2) ${ }_{2} \mathrm{~K}$ in the bilayer. A detailed description of the simulated systems is given in Table S1 (Supplementary material). It has been shown via MD simulations using the MARTINI coarse grained model that MG2 forms large-sized, disordered toroidal pores in DPPC bilayers [13]. These simulations have further shown that neither six or twelve copies of the MG2 monomer were sufficient to induce pore formation in a membrane composed of 512 lipid molecules. Instead, at least twenty-four MG2 copies were required to induce the formation of pores in the membrane. We have also run simulations of systems containing six or twelve copies of MG2 in a POPE:POPG bilayer containing 520 lipid molecules (Fig. S3 in Supplementary material). Consistent with the previous simulations for MG2 in DPPC bilayers, there was no pore formation at the simulated concentration conditions regardless of the distribution of MG2 monomers on one or both sides of the bilayer. However, these simulations provided a concentration threshold for pore formation by MG2 in POPE:POPG bilayers. The monomer threshold values were then used for simulations of $(\mathrm{MG} 2)_{2} \mathrm{~K}$ which preserved the same peptide:lipid ratio as in the simulations of the MG2 monomer. MD simulations of (MG2) ${ }_{2} \mathrm{~K}$ revealed a lower concentration threshold for pore formation compared with the monomeric peptide, as shown in Fig. S4 in the Supplementary material. Pore formation was observed for all systems containing twelve copies of (MG2) ${ }_{2} \mathrm{~K}$ regardless of the intial conformation or bilayer distribution of the peptide (Fig. 5). Our simulations suggest that (MG2) ${ }_{2} \mathrm{~K}$ promotes the formation of disordered toroidal pores which can allow the flow of solvent molecules (Fig. 5). These pores appear much alike the pores formed by MG2 [13] but they can be formed at lower concentrations of the peptide in the dimeric form.

Vesicle experiments and MD simulations revealed a lower concentration threshold for pore formation compared with the monomeric peptide. Taken together, the results may be rationalized as indicating that $(\mathrm{MG} 2)_{2} \mathrm{~K}$ is expected to be much more disruptive for E. coli membranes than MG2, which may actually explain the increased bactericidal activity of $(\mathrm{MG} 2)_{2} \mathrm{~K}$.

The interpretation of our results as explanation of the higher activity for the dimer is consistent with proposals according to which the formation of peptide dimers/oligomers seems essential to trigger peptide reorientation and pore formation [60,62]. In addition, the rate-limiting step is pore formation via peptide self-assembly within the membrane $[63,64]$. In the specific case of MG2 dimers, Dempsey et al. [45], Mukai et al. [44] and Arnusch et al. [65] found an increased membrane permeability for different dimeric versions. In a recent study, Zerweck and co-workers have demonstrated for MG2 and PLGA that a stronger peptide-peptide interaction (measured as free energy of dimerization) appears to be directly correlated with a higher membrane leakage rate [60]. Based on these collections of data, we propose a model for the mechanism of action of MG2 and (MG2) ${ }_{2} \mathrm{~K}$ in the schematic diagram of Fig. 6. In this model, after the "binding state" the monomeric peptides need to self-assemble to reach the so-called "assembled state". Only then would the peptide molecules be able to form a toroidal pore. In contrast, the "pre-assembled state" of the dimeric peptides leads to a fast pore formation, without the need of an aggregation process. Unlike peptide adsorption, peptides assembling is a slow process (the rate-limiting step), which would be favored for the dimer, leading to a faster pore formation.

In the model of Fig. 6, we assume that MG2 form "toroidal pores", as proposed in the literature $[11,12]$, with peptides tightly bound to the polar lipid groups and promoting bilayer bending [47,66,67]. However, we cannot discard the possibility of MG2 forming "disordered toroidal pores" [57]. For (MG2) ${ }_{2} \mathrm{~K}$, our results support the 


$$
\mathrm{t}=0
$$

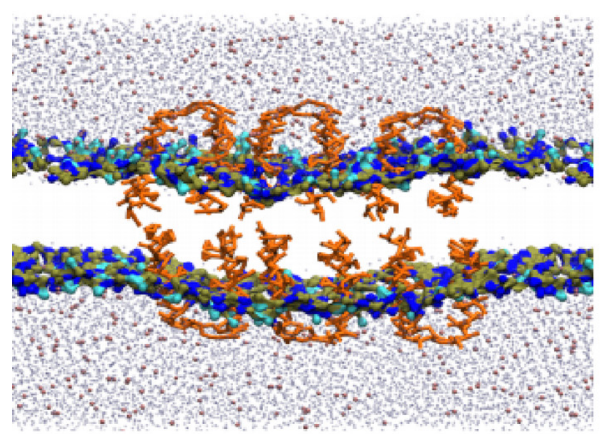

$\mathrm{t}=4 \mathrm{us}$

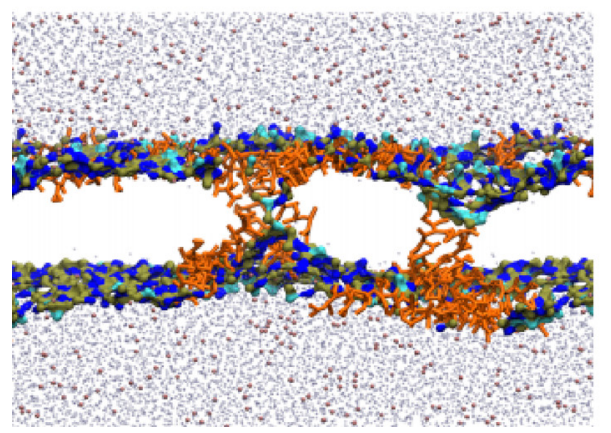

$\mathrm{t}=2$ us

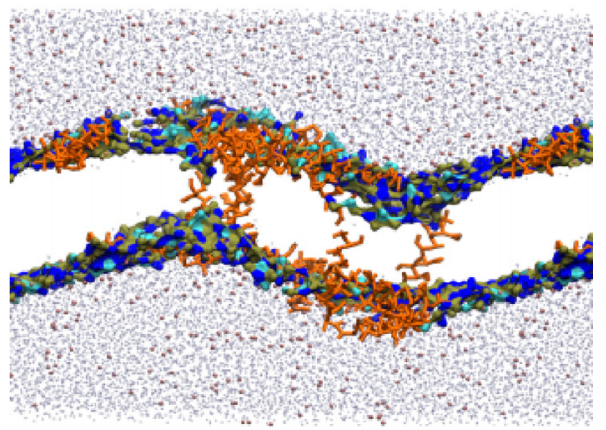

$\mathrm{t}=4$ us

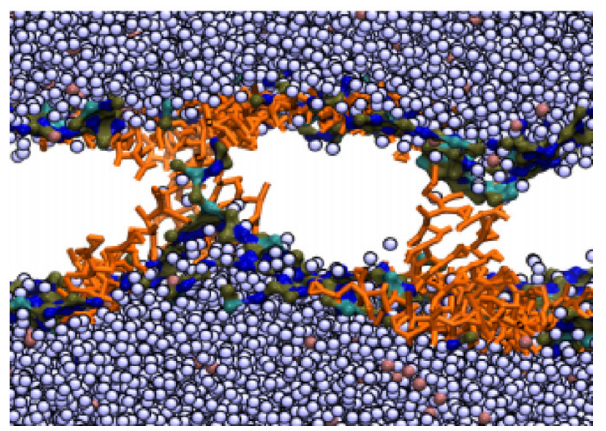

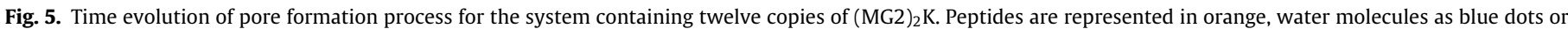

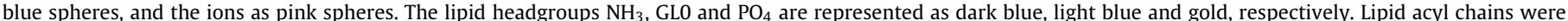

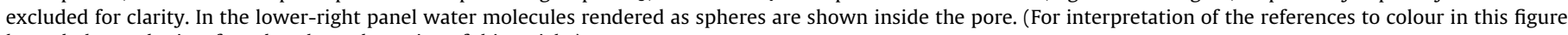
legend, the reader is referred to the web version of this article.)

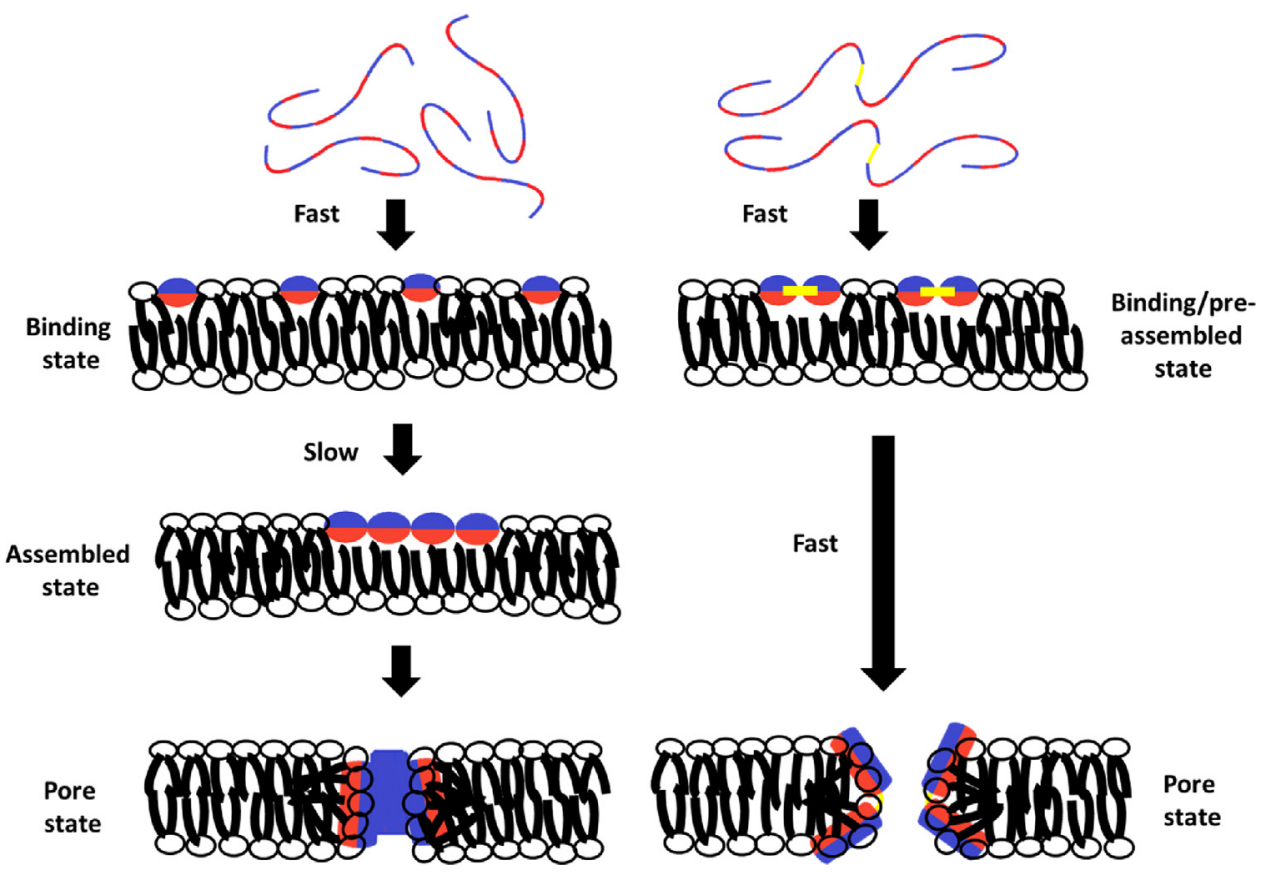

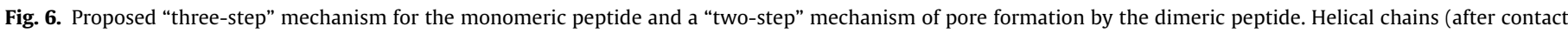

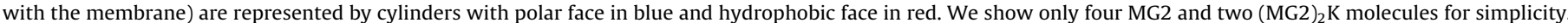
(For interpretation of the references to colour in this figure legend, the reader is referred to the web version of this article.) 
formation of disordered toroidal pores which can allow the flow of solvent molecules, and thus cause leakage of the bacteria cell content.

\section{Conclusions}

We have combined two experimental approaches, Langmuir monolayers and large unilamellar vesicles, and computational simulations to elucidate the molecular mechanism by which the "pre-assembling state" of the magainin dimer exerts its disruptive activity on $E$. coli cell membranes. We have shown that the "pre-assembling state" of (MG2) ${ }_{2} \mathrm{~K}$ enhances pore formation with a reduced number of molecules required to kill E. coli. In summary, pore formation is favored by dimerization, with the proximity and orientation of peptide chains imposed by dimerization being responsible for the reduced MIC value and fast antimicrobial activity. Overall, this study contributes useful information for the design of new dimeric AMPs.

\section{Author contributions}

ENL conceived the study, performed and analyzed experimental data, and wrote the paper. TMN conceived the study and analyzed experimental data. LC analyzed experimental data. EMC conceived the study and oversaw all work. GCAH performed and analyzed theoretical data. TAS performed and analyzed theoretical data and oversaw all work. ONOJ conceived the study and oversaw all work. All authors reviewed the results and approved the final version of the manuscript.

\section{Acknowledgments}

The authors are grateful to FAPESP (2013/07600-3, 2013/14262-7, 2015/16857-3), CAPES, FACEPE (APQ-07321.06/14), BioMol/CAPES (BioComp 23038.004630/2014-35) and $\mathrm{CNPq}$ (Brazil) for the financial support. Computational resources were provided by the High Performance Computing Center North (HPC2N) at Umeå University, Sweden.

\section{Appendix A. Supplementary data}

Supplementary data associated with this article can be found, in the online version, at https://doi.org/10.1016/j.colsurfb.2018.04. 034.

\section{References}

[1] A.H. Holmes, L.S. Moore, A. Sundsfjord, M. Steinbakk, S. Regmi, A. Karkey, P.J. Guerin, L.J. Piddock, Understanding the mechanisms and drivers of antimicrobial resistance, Lancet 387 (2016) 176-187.

[2] E. Toner, A. Adalja, G.K. Gronvall, A. Cicero, T.V. Inglesby, Antimicrobial resistance is a global health emergency, Health Secur. 13 (2015) 153-155.

[3] A.K. Marr, W.J. Gooderham, R.E. Hancock, Antibacterial peptides for therapeutic use: obstacles and realistic outlook, Curr. Opin. Pharmacol. 6 (2006) 468-472

[4] G. Roscia, C. Falciani, L. Bracci, A. Pini, The development of antimicrobial peptides as new antibacterial drugs, Curr. Protein Pept. Sci. 14 (2013) 641-649.

[5] T.-H. Lee, K.N. Hall, M.-I. Aguilar, Antimicrobial peptide structure and mechanism of action: a focus on the role of membrane structure, Curr. Top. Med. Chem. 16 (2016) 25-39.

[6] C.D. Fjell, J.A. Hiss, R.E. Hancock, G. Schneider, Designing antimicrobial peptides: form follows function, Nat. Rev. Drug Discov. 11 (2012) 37-51.

[7] L.M. Yin, M.A. Edwards, J. Li, C.M. Yip, C.M. Deber, Roles of hydrophobicity and charge distribution of cationic antimicrobial peptides in peptide-membrane interactions, J. Biol. Chem. 287 (2012) 7738-7745.

[8] A. Schmidtchen, M. Pasupuleti, M. Malmsten, Effect of hydrophobic modifications in antimicrobial peptides, Adv. Colloid Interface Sci. 205 (2014) 265-274.
[9] M. Zasloff, Magainins, a class of antimicrobial peptides from Xenopus skin: isolation, characterization of two active forms, and partial cDNA sequence of a precursor, Proc. Natl. Acad. Sci. U. S. A. 84 (1987) 5449-5453.

[10] W. Lee, D.G. Lee, Magainin 2 induces bacterial cell death showing apoptotic properties, Curr. Microbiol. 69 (2014) 794-801.

[11] K.T. Nguyen, S.V. Le Clair, S. Ye, Z. Chen, Molecular interactions between magainin 2 and model membranes in situ, J. Phys. Chem. B 113 (2009) $12358-12363$.

[12] Y. Imura, N. Choda, K. Matsuzaki, Magainin 2 in action: distinct modes of membrane permeabilization in living bacterial and mammalian cells, Biophys. J. 95 (2008) 5757-5765.

[13] K.P. Santo, M.L. Berkowitz, Difference between magainin-2 and melittin assemblies in phosphatidylcholine bilayers: results from coarse-grained simulations, J. Phys. Chem. B 116 (2012) 3021-3030.

[14] M.A.S. Karal, J.M. Alam, T. Takahashi, V. Levadny, M. Yamazaki, Stretch-activated pore of the antimicrobial Peptide, magainin 2, Langmuir 31 (2015) 3391-3401

[15] M. Yeaman, N. Yount, Mechanisms of antimicrobial peptide action and resistance, Pharmacol. Rev. 55 (2003) 27-55.

[16] M.M. Welling, C.P. Brouwer, W. van't Hof, E.C.I. Veerman, A.V.N. Amerongen, Histatin-derived monomeric and dimeric synthetic peptides show strong bactericidal activity towards multidrug-resistant Staphylococcus aureus in vivo, Antimicrob. Agents Chemother. 51 (2007) 3416-3419.

[17] L. Zhou, S. Liu, L. Chen, J. Li, L. Ong, L. Guo, T. Wohland, C. Tang, R. Lakshminarayanan, J. Mavinahalli, The structural parameters for antimicrobial activity, human epithelial cell cytotoxicity and killing mechanism of synthetic monomer and dimer analogues derived from hBD3 C-terminal region, Amino Acids 40 (2011) 123-133.

[18] N.A. Santos-Filho, E.N. Lorenzon, M.A. Ramos, C.T. Santos, J.P. Piccoli, T.M. Bauab, A.M. Fusco-Almeida, E.M. Cilli, Synthesis and characterization of an antibacterial and non-toxic dimeric peptide derived from the C-terminal region of Bothropstoxin-I, Toxicon 103 (2015) 160-168.

[19] J.Y. Lee, S.T. Yang, S.K. Lee, H.H. Jung, S.Y. Shin, K.S. Hahm, J.I. Kim, Salt-resistant homodimeric bactenecin, a cathelicidin-derived antimicrobial peptide, FEBS J. 275 (2008) 3911-3920.

[20] E.N. Lorenzón, P.R. Sanches, L.G. Nogueira, T.M. Bauab, E.M. Cilli, Dimerization of aurein 1.2: effects in structure, antimicrobial activity and aggregation of Cândida albicans cells, Amino Acids 44 (2013) 1521-1528.

[21] I.H. Lee, Y.S. Lee, C.H. Kim, C.R. Kim, T. Hong, L. Menzel, L.M. Boo, J. Pohl, M.A. Sherman, A. Waring, Dicynthaurin: an antimicrobial peptide from hemocytes of the solitary tunicate Halocynthia aurantium, Biochimica et Biophysica Acta (BBA)-Gen. Subj. 1527 (2001) 141-148.

[22] W.L. Zhu, S.Y. Shin, Antimicrobial and cytolytic activities and plausible mode of bactericidal action of the cell penetrating peptide penetratin and its lys-linked two-stranded peptide, Chem. Biol. Drug Des. 73 (2009) 209-215.

[23] S.T. Yang, J.I. Kim, S.Y. Shin, Effect of dimerization of a beta-turn antimicrobial peptide PST13-RK, on antimicrobial activity and mammalian cell toxicity, Biotechnol. Lett. 31 (2009) 233-237.

[24] E. Lorenzón, N. Santos-Filho, M. Ramos, T. Bauab, I. Camargo, E. Cilli, C-terminal lysine-linked magainin 2 with increased activity against multidrug-resistant bacteria, Protein Pept. Lett. 23 (2016) 738-747.

[25] R.B. Merrifield, Solid phase peptide synthesis. I. The synthesis of a tetrapeptide, J. Am. Chem. Soc. 85 (1963) 2149-2154.

[26] J.C. Damalio, T.M. Nobre, J.L. Lopes, O.N. Oliveira, A.P. Araújo, Lipid interaction triggering Septin 2 to assembly into $\beta$-sheet structures investigated by Langmuir monolayers and PM-IRRAS, Biochim. Biophys. Acta 1828 (2013) 1441-1448.

[27] R. Mendelsohn, G. Mao, C.R. Flach, Infrared reflection-absorption spectroscopy: principles and applications to lipid-protein interaction in Langmuir films, Biochimica et Biophysica Acta (BBA)-Biomembr. 1798 (2010) $788-800$

[28] E.F. Vicente, T.M. Nobre-Pavinatto, F.J. Pavinatto, O. N de Oliveira Junior, A.J. da Costa Filho, E.M. Cilli, N-terminal microdomain peptide from human dihydroorotate dehydrogenase: structure and model membrane interactions, Protein Pept. Lett. 22 (2015) 119-129.

[29] S.J. Marrink, H.J. Risselada, S. Yefimov, D.P. Tieleman, A.H. De Vries, The MARTINI force field: coarse grained model for biomolecular simulations, J. Phys. Chem. B 111 (2007) 7812-7824.

[30] S.J. Marrink, A.H. De Vries, A.E. Mark, Coarse grained model for semiquantitative lipid simulations, J. Phys. Chem. B 108 (2004) 750-760.

[31] B. Hess, C. Kutzner, D. Van Der Spoel, E. Lindahl, GROMACS 4: algorithms for highly efficient, load-balanced, and scalable molecular simulation, J. Chem. Theory Comput. 4 (2008) 435-447.

[32] J. Gesell, M. Zasloff, S.J. Opella, Two-dimensional 1H NMR experiments show that the 23-residue magainin antibiotic peptide is an alpha-helix in dodecylphosphocholine micelles, sodium dodecylsulfate micelles, and trifluoroethanol/water solution, J. Biomol. NMR 9 (1997) 127-135.

[33] T.A. Wassenaar, H.I. Ingoílfsson, R.A. Böckmann, D.P. Tieleman, S.J. Marrink, Computational lipidomics with insane: a versatile tool for generating custom membranes for molecular simulations, J. Chem. Theory Comput. 11 (2015) 2144-2155.

[34] M. Parrinello, A. Rahman, Polymorphic transitions in single crystals: a new molecular dynamics method, J. Appl. Phys. 52 (1981) 7182-7190.

[35] G. Bussi, D. Donadio, M. Parrinello, Canonical sampling through velocity rescaling, J. Chem. Phys. 126 (2007) 014101 
[36] W. Humphrey, A. Dalke, K. Schulten, VMD: visual molecular dynamics, J. Mol. Graph. 14 (1996) 33-38.

[37] Y. Tamba, M. Yamazaki, Magainin 2-induced pore formation in the lipid membranes depends on its concentration in the membrane interface, J. Phys. Chem. B 113 (2009) 4846-4852.

[38] C. Kim, J. Spano, E.K. Park, S. Wi, Evidence of pores and thinned lipid bilayers induced in oriented lipid membranes interacting with the antimicrobial peptides, magainin-2 and aurein-3.3, Biochim. Biophys. Acta 1788 (2009) $1482-1496$.

[39] K. Matsuzaki, O. Murase, N. Fujii, K. Miyajima, An antimicrobial peptide, magainin 2, induced rapid flip-flop of phospholipids coupled with pore formation and peptide translocation, Biochemistry 35 (1996) 11361-11368.

[40] M. Zasloff, B. Martin, H.C. Chen, Antimicrobial activity of synthetic magainin peptides and several analogues, Proc. Natl. Acad. Sci. U. S. A. 85 (1988) 910-913.

[41] E. Han, H. Lee, Effects of PEGylation on the binding interaction of magainin 2 and tachyplesin I with lipid bilayer surface, Langmuir 29 (2013) 14214-14221.

[42] T. Unger, Z. Oren, Y. Shai, The effect of cyclization of magainin 2 and melittin analogues on structure, function, and model membrane interactions: implication to their mode of action, Biochemistry 40 (2001) 6388-6397.

[43] R. Bessalle, A. Kapitkovsky, A. Gorea, I. Shalit, M. Fridkin, All-D-magainin: chirality, antimicrobial activity and proteolytic resistance, FEBS Lett. 274 (1990) 151-155.

[44] Y. Mukai, Y. Matsushita, T. Niidome, T. Hatekeyama, H. Aoyag, Parallel and antiparallel dimers of magainin 2: their interaction with phospholipid membrane and antibacterial activity, J. Pept. Sci. 8 (2002) 570-577.

[45] C.E. Dempsey, S. Ueno, M.B. Avison, Enhanced membrane permeabilization and antibacterial activity of a disulfide-dimerized magainin analogue, Biochemistry 42 (2003) 402-409.

[46] J. Strauss, A. Kadilak, C. Cronin, C.M. Mello, T.A. Camesano, Binding, inactivation, and adhesion forces between antimicrobial peptide cecropin P1 and pathogenic E. coli, Colloids Surf. B: Biointerfaces 75 (2010) 156-164.

[47] K.A. Brogden, Antimicrobial peptides: pore formers or metabolic inhibitors in bacteria? Nat. Rev. Microbiol. 3 (2005) 238-250.

[48] T.M. Nobre, F.J. Pavinatto, L. Caseli, A. Barros-Timmons, P. Dynarowicz-Łątka, O.N. Oliveira, Interactions of bioactive molecules \& nanomaterials with Langmuir monolayers as cell membrane models, Thin Solid Films 593 (2015) $158-188$.

[49] R. Maget-Dana, The monolayer technique: a potent tool for studying the interfacial properties of antimicrobial and membrane-lytic peptides and their interactions with lipid membranes, Biochimica et Biophysica Acta (BBA)-Biomembr. 1462 (1999) 109-140.

[50] R. Volinsky, S. Kolusheva, A. Berman, R. Jelinek, Investigations of antimicrobial peptides in planar film systems, Biochimica et Biophysica Acta (BBA)-Biomembr. 1758 (2006) 1393-1407.

[51] K.D. de Souza, K.R. Perez, N. Durán, G.Z. Justo, L. Caseli, Interaction of violacein in models for cellular membranes: regulation of the interaction by the lipid composition at the air-water interface, Colloids Surf. B: Biointerfaces 160 (2017) 247-253.

[52] A. Hädicke, A. Blume, Binding of short cationic peptides (KX) $4 \mathrm{~K}$ to negatively charged DPPG monolayers: competition between electrostatic and hydrophobic interactions, Langmuir 31 (2015) 12203-12214.
[53] L. Caseli, M.L. Moraes, V. Zucolotto, M. Ferreira, T.M. Nobre, M.E.D. Zaniquelli, U.P. Rodrigues Filho, O.N. Oliveira, Fabrication of phytic acid sensor based on mixed phytase-lipid Langmuir-Blodgett films, Langmuir 22 (2006) 8501-8508.

[54] K. Matsuzaki, O. Murase, N. Fujii, K. Miyajima, Translocation of a channel-forming antimicrobial peptide magainin 2 , across lipid bilayers by forming a pore, Biochemistry 34 (1995) 6521-6526.

[55] A. Barth, C. Zscherp, What vibrations tell about proteins, Q. Rev. Biophys. 35 (2002) 369-430.

[56] B.L. Frey, R.M. Corn, S.C. Weibel, Polarization-modulation approaches to reflection-absorption spectroscopy, in: Handbook of Vibrational Spectroscopy, John Wiley \& Sons, Ltd, 2006.

[57] D. Sengupta, H. Leontiadou, A.E. Mark, S.J. Marrink, Toroidal pores formed by antimicrobial peptides show significant disorder, BBA: Biomembr. 1778 (2008) 2308-2317.

[58] A.L. Russell, A.M. Kennedy, A.M. Spuches, W.S. Gibson, D. Venugopal, D. Klapper, A.H. Srouji, J.B. Bhonsle, R.P. Hicks, Determining the effect of the incorporation of unnatural amino acids into antimicrobial peptides on the interactions with zwitterionic and anionic membrane model systems, Chem. Phys. Lipids 164 (2011) 740-758.

[59] T.M. Domingues, B. Mattei, J. Seelig, K.R. Perez, A. Miranda, K.A. Riske, Interaction of the antimicrobial peptide gomesin with model membranes: a calorimetric study, Langmuir 29 (2013) 8609-8618.

[60] J. Zerweck, E. Strandberg, J. Bürck, J. Reichert, P. Wadhwani, O. Kukharenko, A.S. Ulrich, Homo-and heteromeric interaction strengths of the synergistic antimicrobial peptides PGLa and magainin 2 in membranes, Eur. Biophys. J. 45 (2016) 535-547.

[61] E. Lorenzón, K. Riske, G. Troiano, G. Da Hora, T. Soares, E. Cilli, Effect of dimerization on the mechanism of action of aurein 1.2, Biochimica et Biophysica Acta (BBA)-Biomembr. 1858 (2016) 1129-1138.

[62] K. Hristova, C.E. Dempsey, S.H. White, Structure, location, and lipid perturbations of melittin at the membrane interface, Biophys. J. 80 (2001) $801-811$.

[63] K. Matsuzaki, O. Murase, K. Miyajima, Kinetics of pore formation by an antimicrobial peptide, magainin 2, in phospholipid bilayers, Biochemistry 34 (1995) 12553-12559.

[64] Z. Ningsih, M.A. Hossain, J.D. Wade, A.H. Clayton, M.L. Gee, Slow insertion kinetics during interaction of a model antimicrobial peptide with unilamellar phospholipid vesicles, Langmuir 28 (2011) 2217-2224.

[65] C.J. Arnusch, H. Branderhorst, B. de Kruijff, R.M. Liskamp, E. Breukink, R.J. Pieters, Enhanced membrane pore formation by multimeric/oligomeric antimicrobial peptides, Biochemistry 46 (2007) 13437-13442.

[66] E.N. Lorenzon, G.F. Cespedes, E.F. Vicente, L.G. Nogueira, T.M. Bauab, M.S, Castro, E.M. Cilli, Effects of dimerization on the structure and biological activity of antimicrobial peptide Ctx-Ha, Antimicrob. Agents Chemother. 56 (2012) 3004-3010.

[67] G.F. Cespedes, E.N. Lorenzon, E.F. Vicente, M.J. Soares Mendes-Giannini, W. Fontes, M.d.S. Castro, E.M. Cilli, Mechanism of action and relationship between structure and biological activity of Ctx-Ha: a new ceratotoxin-like peptide from hypsiboas albopunctatus, Protein Pept. Lett. 19 (2012) 596-603. 